\title{
Principal-Principal Conflict in the Governance of the Chinese Public Corporation 中国上市公司治理中的所有者冲突现象
}

\author{
Yiyi Su (苏依依), Dean Xu (许德音) and \\ Phillip H. Phan (潘庆财)
}

ABSTRACT 摘要

我们通过考察股权的集中程度研究了企业所有者冲突, 即企业大小股东之间所有权目标的不 一致性, 对中国企业董事会中代理成本的影响。基于1999至2003年间上海和深圳两地上市公 司的数据, 我们发现, 股权集中度与董事收入水平、董事会规模以及独立董事的比例之间均 存在呈U型的曲线关系。这些结果显示企业所有者之间目标的不一致提高了代理成本。

关键词：代理成本、董事会、中国、股权集中度、所有者冲突 


\section{The Effects of Federalism on Productivity in Chinese Firms}

\section{联邦制对中国企业生产率的影响}

\section{Sean M. Dougherty and Robert H. McGuckin}

ABSTRACT 摘要

本研究探讨了政府治理和民营所有制的结构如何影响了中国企业的生产效率。我们使用了中 国最近十年的工业统计数据, 覆盖了自 1995年以来的 23,000 家大中型工业企业。结果发现, 政府的放权---- “联邦制”- -..--在提高集体企业、国有企业和公-私合营企业的效率方面都 扮演了重要的角色。这一结果验证了政府在市场有效运作中的关键作用, 为转型经济学的理 论假设提供了支持。

关键词：联邦制、管辖权、分权、所有制、生产效率 


\section{Guanxi Dynamics: Shifts in the Closeness of Ties Between Chinese Coworkers 动态关系 : 同事之间亲密程度的变化}

\section{Xiao-Ping Chen (陈晓萍) and Siqing Peng (彭泗清)}

ABSTRACT 摘要

本文采用动态关系的眼光探索了同事之间关系亲密程度的变化过程。我们对来自中国大陆的 中高级企业管理人员进行了两个研究来探索同事关系的动态性质和内容。结果发现在亲密同 事关系中包含了两个既关联又有区别的要素, 即工具性和情感性要素。与此同时, 我们发现 了可能加强或削弱同事关系的一些行为事件, 并且发现这些事件对关系亲密程度的影响与两 个同事之间目前的关系好坏有着密切的联系。相对于目前关系比较疏远的同事来说, 负面行 为事件对两个亲密同事关系的损坏程度要严重得多; 反过来, 相对于目前关系比较亲密的同 事来说, 正面行为事件对两个疏远同事关系的增进程度则要显著得多。本文就这些研究结果 对末来关系理论的发展和实践进行了详细讨论。

关键词 : 关系、同事关系、关系亲密程度、关系亲密程度的变化 


\title{
Framing China: Transformation and Institutional Change through Go-evolution
}

\section{构建中国：通过共同演化实现转型和制度变化}

\section{Barbara Krug and Hans Hendrischke}

\begin{abstract}
摘要
本文从新制度理论的角度解释了中国地方商业体制的多样性及其形成机制。我们认为, 中国 商业体制是在商业一政府维度和微观一宏观维度上演化形成的。这一过程中涉及了政府间的 制度竞争、企业与企业和企业与政府间的网络互动、以及公私联营的公司治理等要素。我们 发现：(1) 中国出现的商业体制是微观层面上的地方政府间相互竞争的产物。这种竞争降 低了对国家 (宏观层面) 制度的需求, 并影响着国家 (包括国际) 政策在地方的实施; (2) 政 府与企业间的互动是透过构建网络而实现的, 这种互动既体现了经济理性又反映了文化传统 和习俗：(3) 企业与地方政府的互动实现了生产要素的重新整合和对企业和产业的重组, 使 之与地方利益保持一致。最后, 我们认为中国企业惊人的适应能力、地方政府腐败的风险和 正式控制的缺之是构成具有差异性的地方商业体制的三个要素。而这些地方商务体制则是通 过一个具有纽带性质的综合制度架构衔接起来。
\end{abstract}

关键词：共同演化、中国商业体制、制度变化、分权制、网络、地方自治 


\title{
From Contract Manufacturing to Own Brand Management: The Role of Learning and Cultural Heritage Identity
}

\section{从代工迈向自创品牌：学习和文化遗产同感的影响}

\section{Ching Horng (洪清德) and Wayne Chen (陈韦宇)}

\begin{abstract}
摘要
为品牌客户贴牌生产的台湾厂商近年来已有部分朝向自创品牌迈进。本研究探讨三个影响自 创品牌绩效的因素：向关键客户学习, 向关键子公司学习, 以及厂商本身的文化遗产认同 感。研究结果发现向子公司学习和文化认同感皆对自创品牌绩效有正面影响。我们还发现文 化认同感对向客户学习和自创品牌绩效两者之间的关系有负面调节效果, 这一结果有悖于我 们的直觉判断。上述发现虽然只是初步结果, 但我们建议未来研究可优先观察不对等关系伙 伴以更加深人探讨文化认同感和光荣感扮演的角色。
\end{abstract}

关键词：自创品牌、文化传统认同感、客户学习、子公司学习 